\section{Uso de Tecnologias Para Detecção de Fraudes na Pandemia da Covid-19}

\section{Erivanilson Freitas de Oliveira}

UERN - Universidade do Estado do Rio Grande do Norte nilsinfreitas@gmail.com

Camila Karen Alves Pedrosa

UFERSA - Universidade Federal Rural do Semi-Àrido camilakarenn21@gmail.com

\section{Sérgio Luiz Pedrosa Silva}

UERN - Universidade do Estado do Rio Grande do Norte sergiopedrosa@uern.br

\author{
Wênyka Preston Leite Batista da Costa \\ UNP - Universidade Potiguar \\ wenykaleite@uern.br \\ Jandeson Dantas da Silva \\ UNISINOS - Universidade do Vale do Rio dos Sinos \\ jandesondantas@uern.br
}

\section{Resumo}

Durante a pandemia do coronavírus, os entes públicos receberam verbas governamentais, para socorrer a população, oportunamente, gestores corruptos passaram a obter benefícios pessoais com essas verbas, dessa forma a Controladoria Geral da União (CGU), para inibir essas condutas, utilizou de Tecnologias da Informação e Comunicação (TICs) para promover o processo de detecção de fraudes. 0 estudo objetivou analisar a eficácia das TICs utilizadas pela CGU na deteç̧ão de fraudes na aplicação de recursos da Covid-19. A metodologia evidenciou-se como qualitativa, para se descrever dados que foram levantados, por meio de busca em sites do Governo Federal, onde foi realizada análise de conteúdo, com a utilização das metodologias de estudo da fraude. Como principais resultados, destacou-se que as TICs utilizadas pela CGU, têm sido ferramentas úteis na detecção de fraudes, principalmente, na pandemia do Covid-19, pois, conseguiu-se detectar $\mathrm{R} \$ 11,2$ bilhões de recursos que foram utilizados irregularmente, no programa do auxílio emergencial, com cadastro irregulares e em processos licitatórios, com vícios processuais; utilizou-se como parâmetro para mensurar as detecções, a estimativa do custo da corrupção, evidenciando, que apesar das inconsistências detectadas, ainda existe um volume significativo de recursos que podem estarem envoltos em fraudes. A principal contribuição desse estudo, destaca-se no conhecimento das TICs que são utilizadas pela CGU para combater ilícitos com verbas públicas federais, destacando resultados expressivos dessas ferramentas no acompanhamento da aplicação de recursos da Covid-19.

Palavras-Chave: Tecnologias da Informação e Comunicação. Fraudes Públicas. Pandemia Covid-19.
ISSN: 1984-6266

Recebimento:

04/01/2021

Aprovação:

24/02/2021

Editor responsável pela aprovação do artigo:

Dra. Luciana Klein

Editor responsável pela edição do artigo:

Dra. Luciana Klein

Avaliado pelo sistema:

Double Blind Review

A reprodução dos artigos, total ou parcial, pode ser feita desde que citada a fonte.

PROGRAMA DE PÓS-GRADUAÇÃO EM CONTABILIDADE MESTRADO E DOUTORADO

DOI:

http://dx.doi.org/10.5380/rcc.v13i1.78756 


\section{THE USE OF FRAUD DETECTION TECHNOLOGIES IN THE COVID-19 PANDEMIC}

\section{ABSTRACT}

During a coronavirus pandemic, public entities received government funds to help the population, in a timely manner, corrupt managers began to obtain personal benefits from these funds, thus the Federal Comptroller General (CGU), to inhibit these conducts, used Technologies Information and Communication (ICT) to promote the fraud detection process. The study aimed to analyze the effectiveness of ICTs technological tools used by CGU in detecting fraud in the application of resources from Covid-19 federal resources to combat a Covid-19 pandemic. As a problem issue, we sought to verify whether the Information and Communication Technologies (ICT) used by the Federal Comptroller General (CGU), were effective to monitor the federal public resources made available to combat Covid-19. The methodology proved to be qualitative, in order to describe data that were collected, through search on Federal Government websites, where content analysis was carried out, using the fraud study and research methodologies of KPMG (2015). As main results, it was highlighted the finding that ICT affectivity, used by the CGU, have been useful tools in the detection of fraud, mainly in the covid-19 pandemic, since it was possible to detect $R \$ 11.2$ billions of resources that were used irregularly, in the emergency aid program, with irregular registration and in bidding processes, with procedural defects; was used as a parameter to measure the detections, according to the estimated cost of corruption, showing that despite the detected inconsistencies, there is still a significant volume of resources that may be involved in fraud. public resources, in this way the GCU managed to approach this parameter, showing itself effective with its ICT, s. The main contribution of this study, stands out in the knowledge of ICTs Information and Communication technologies that are used by CGU to combat illicit activities with federal public funds, highlighting the expressive results of these tools in monitoring the application of resources from covid-19. to combat the covid-19 pandemic. For future research on the topic, it is necessary to raise other variables of the resulting factors, such as age, working time, function and other variables, in order to promote a more in-depth study on the profile of the fraudster.

Keywords: Information and Communication Technologies. Public Fraud. Covid-19 Pandemic.

\section{Introdução}

A pandemia da Covid-19 se iniciou como um surto de pneumonia desconhecida, relatado inicialmente na China, na cidade Wuhan, em dezembro de 2019. Os casos foram identificados, principalmente entre os chineses que frequentavam um mercado de frutos-do-mar, na província de Hunei. Este surto foi identificado, através das pessoas que tinham contato direto, com os animais comercializados nesse mercado (Sousa Júnior, 2020; Anderson, Heesterbeek, Klinkenberg \& Hollingsworth, 2020).

Diante desse fato, passou-se a disseminar em vários países, em março de 2019, a Organização Mundial da Saúde (OMS) declarou a pandemia da Covid-19, vírus que infectou milhões de pessoas em todo 0 mundo, promovendo a morte de muitos cidadãos, principalmente de pessoas de grupos de riscos, como diabéticos, obesos, hipertensos e outras comorbidades (Rodriguez-Morales \& Gallego, 2020; Chaves \& Bellei, 2020; Sousa Júnior, 2020; Anderson et al., 2020).

No entanto, em situações de calamidade, os municípios enfrentam dificuldades econômicas e sociais, onde precisam atender as necessidades dos cidadãos, promovendo, operações urgentes para atender as carências sanitárias nos municípios. De acordo com Open Knowledge Brasil (OKBR), medidas urgentes devem ser implementadas. Para isso, o Governo Federal brasileiro flexibilizou às contratações de bens e serviços através da Lei Federal n 13.979/2020, complementada pelas Medidas Provisórias n 926 e 951/2020, onde 
estabeleceram medidas excepcionais para as contratações (Nobre \& Aguiar, 2020; Feltrini, Gonçalves \& Pinho Filho, 2020).

Nesse cenário de excepcionalidade, surgem pessoas oportunistas, que aproveitam da situação, para obterem benefícios pessoais, com as verbas que são destinadas a atender à população. Como exemplo, de casos de desvios de verbas na área da saúde, destaca-se o escândalo da máfia dos sanguessugas, em 2006, onde 112 parlamentares brasileiros, foram investigados sob suspeita de terem recebido suborno de uma empresa de ambulâncias, a 'Planam', para destinar verbas federais para compra de veículos, com cerca de R\$ 110 milhões de reais em ações ilícitas (Sousa Júnior, 2020; Carvalho, 2020; Berlt, Bender Filho \& Tristão, 2017; Queiroz, 2016).

Essas práticas não se evidenciam somente no Brasil, na pandemia do Ebola na África em 2014, constatou-se o desvio de cerca de $\$ 5$ milhões de dólares de recursos, doados pela Cruz Vermelha e organizações internacionais para ajudar na erradicação da pandemia, nas aquisições de produtos e serviços. O Brasil, igualmente, merece o olhar atento dos órgãos de controle do Estado, pois, de acordo com a OKBR o índice de corrupção no Brasil em 2020, atingiu 35 pontos, sendo um índice baixo em comparação a outros países, principalmente na América do sul, ficando atrás de argentina, Chile e Paraguai (Florêncio Filho \& Zanon, 2020; OKBR, 2020).

Embora a legislação no Brasil exija transparência e lisura nas contratações públicas, pois, a Lei de Acesso á Informação (LAl), assegura a transparência fiscal e o conhecimento de dados dos indivíduos que transacionam com o poder público, em que, destaca-se a OKBR, que com uma metodologia própria, realizando o acompanhamento da transparência, nos sítios eletrônicos sobre aplicação dos recursos da Covid-19, nas capitais e estados brasileiros, constatando que esses, atendem plenamente os requisitos da LAI, mas quando se trata de informações desejáveis (não obrigatórias), os entes, na sua maioria não publicam essas informações (Caleffi \& Raupp, 2017; LAl nº 15.527/11).

Dessa forma, o cenário de corrupção, evidenciou-se, com fraudes no auxílio emergencial, programa, para as pessoas em vulnerabilidade social, onde cidadãos que não possuíam os requisitos para participarem do programa, realizaram o cadastro de forma fraudulenta, ainda a deflagração de operações pela polícia federal para investigar, condutas ilícitas nos processos licitatórios, onde se evidenciou, principalmente, superfaturamento de preços e irregularidades em hospitais de campanha (CGU, 2020; Sousa Filho, 2020; Caleffi \& Raupp, 2017).

Diante desse quadro de corruptibilidade apresentado com os repasses governamentais, a CGU, utilizou-se de TICs, como meio para monitorar a ação dos gestores, na aplicação dos recursos federais. Em dezembro de 2019, a CGU apresentou suas principais tecnologias de combate à fraude, com cinco mecanismos de atuação. Além desse aparato tecnológico, também utilizou a sua infraestrutura e o compartilhamento de informações com outros órgãos, como: polícia federal, Auditoria Geral da União (AGU), Tribunal de Contas dos Estados (TCE), Polícia Rodoviária Federal (PRF), e ministérios do Governo (Bataglia \& Farranha, 2020; CGU, 2020; Sousa Filho, 2020).

Sendo assim, o objetivo dessa pesquisa é analisar a eficácia das ferramentas tecnológicas utilizadas pela CGU na detecção de fraudes na aplicação dos recursos federais para combater a pandemia da Covid-19, para isso realizou-se uma pesquisa qualitativa, com procedimento documental em websites do governo federal (Agência Brasil, 2020; CGU, 2020).

A pesquisa justifica-se, pois, é notório um elevado número de ações realizadas pela Polícia Federal, destacando-se as operações em vários estados do Brasil, com destaque para a região Norte do país com quatro operações deflagradas (Polícia Federal, 2020). Em razão da pandemia da Covid-19, muitos Estados estão promovendo o enfrentamento do coronavírus, buscando tratamento para os infectados e redução dos impactos econômicos, dessa forma, desenvolveram políticas públicas em seus territórios. No que lhe concerne, experiências passadas no Brasil evidenciam que apesar de serem imprescindíveis, essas políticas, aumentamse os riscos de práticas corruptas na gestão pública (Bataglia \& Farranha, 2020, Panis, 2020). 
Como lacuna a ser explorada nesse estudo, destaca-se o custo da corrupção apontado pela Federação das Indústrias do Estado de São Paulo (FIESP), Organização das Nações Unidas (ONU) e Instituto Brasileiro de Planejamento Tributário (IBPT), em que buscou-se verificar a eficácia das TICs na relação ao custo da corrupção apontado por esses órgãos. Além disso, a pesquisa busca contribuir para tornar-se de conhecimento público as TICs utilizadas pela CGU para detecção de fraudes, para que outros entes públicos possam se munir dessas novas tecnologias no combate a atos ilícitos, e para academia buscou-se ampliar a discussão no tocante às fraudes públicas, para que se possa entender o funcionamento desse mecanismo, para que se possa promover barreiras de proteção ao erário.

0 artigo está estruturado, com referencial que tem o objetivo de subsidiar a pesquisa com arcabouço teórico, nessa construção, tratou-se sobre a CGU, TICs, a corrupção com recursos da Covid-19, desenvolvimento da fraude, recursos aplicados na pandemia da Covid-19 e ainda se apresentou estudos anteriores relacionados com o tema, promoveu-se a análise e discussão dos dados coletados, apresentando as considerações finais e as referências utilizadas nesse estudo.

\section{Referencial Teórico}

O referencial teórico proporcionou o arcabouço teórico necessário para realizar as análises dos dados coletados, e promover comparações, evidenciaram-se através de tecnologias digitais utilizadas pelo governo federal, a corrupção com recursos da Covid-19 e o desenvolvimento da fraude e estudos anteriores relacionados com o tema. Como a CGU é o órgão promovedor da utilização de TICs, passa-se a apresentar como se desenvolveu sua criação.

\subsection{A Controladoria Geral da União (CGU)}

A sistemática de Controle Interno na administração pública no Brasil, evidenciou-se na Carta de 1891, com o estabelecimento do controle Externo, através dos Tribunais de Contas da União, no artigo 89 desta carta se estabeleceu incisivamente 0 aprimoramento sobre os Tribunais de Contas, passando a ser destacado em todas as outras constituições que se seguiram (Coimbra, 2006).

Já o Controle Interno, passou a ser evidenciado na Lei $n^{0} 4.320 / 64$, nos artigos 76 a 80, mas a referida lei tratava, especificamente da atividade do controle interno e não de sua estruturação e pormenores dessa atividade. Nesse processo de estruturação, criou-se a Controladoria Geral da União (CGU), através do decreto. $n^{0} 4.304 / 2002$, estabelecendo-se como órgão central do sistema de controle interno do poder executivo federal (Brasil, 2019).

Como órgão de fiscalização central do Governo Federal, a CGU em 2015, aprimorou o antigo Programa de Fiscalização por Sorteios Públicos (PFSP), criado em 2003, como mecanismo para reduzir os níveis de corrupção no âmbito público, onde através de sorteios, aleatórios, seleciona-se 60 municípios com no máximo 500 mil habitantes. Esse Programa foi ampliado em 2015, para três formas de seleção: 'censo', 'matriz de vulnerabilidade' e 'sorteios'. Através dessa sistemática já foram fiscalizados 2,5 mil municípios no Brasil, com um aporte de mais de 30 bilhões de reais, demonstrando-se que em 2015, a CGU já utilizava TICs na fiscalização de verbas governamentais (Brasil, 2015).

A metodologia da PFSP se concluí com um relatório final, em que, evidenciam-se as constatações e registros dos processos analisados, onde o mesmo é encaminhado ao Governo Federal para ajustes de políticas públicas, essa metodologia da CGU constitui em uma relevante ferramenta para combater desvios dos recursos públicos (Caldas, Costa \& Pagliarusi, 2015; Brasil, 2015). Dessa forma, a CGU ampliou as TICs para promover o monitoramento da aplicação dos recursos públicos, em que, apresentam-se esses mecanismos 
utilizados pela CGU (Pascoal, Santos \& Faroni, 2020). Para aprofundamento da atuação das TIC, torna-se necessário evidenciar a sua conceituação e funcionamento, conforme abordado a seguir.

\subsection{Tecnologias da Informação e Comunicação (TICs)}

$\mathrm{Na}$ era digital novas técnicas de detecção de fraudes, foram transformadas, em decorrência do 'DigitalEra Governance', concebida por frameworks como Big Data, Internet das coisas (loT) e inteligência artificial. Nessa nova concepção tecnológica, o Machine Learning ou aprendizado de máquina, surge como mecanismo, utilizado por empresas de auditoria no mundo, com a utilização da inteligência artificial no desenvolvimento de técnicas, com objetivo de organizar conhecimento automaticamente (Jaadi, 2017; Brown-Liburd \& Vasarhelyi, 2015).

Coadunam com esse entendimento Stanisic, Radojevic e Stanic (2019), afirmando que os modelos estatísticos, destacadamente, a regressão logística e o probit, estão sendo substituídos por técnicas de Machine Learning, por promoverem melhores resultados na predição em relação aos modelos estatísticos, mas Bao, Bin, Bin, Yu, \& Zhang (2020), apresentaram estudo, em que utilizam um modelo híbrido, estatístico e inteligência artificial, com resultados satisfatórios na detecção de fraudes.

Nessa conjunção de variáveis estatísticas e inteligência artificial, desenvolveram-se vários modelos para promover a organização inteligente e automática de dados, dentre eles têm-se: máquinas de vetores de suporte, Suport Vector Machine (SVM), que consistem em técnicas de aprendizado, que analisa dados e os reconhecem, através de regressão, processo esse desenvolvido por Vapnik, que têm contribuído principalmente, no meio acadêmico, sendo utilizada em várias áreas, destacando-se a previsão de dados (Vapnik, 2013). Por sua vez, Sundarkumar, Ravi e Siddershwar (2015), utilizaram o SVM para detectar fraudes com seguros de automóveis, em que conseguiram obter $86 \%$ de desempenho, contra $60 \%$ dos modelos estatísticos, na previsão de batidas de automóveis.

Dessa forma, modelos de inteligência artificial, associados a ferramentas estatísticas surgiram na Digital era Governance, para promover o suporte das instituições pública e privadas, pode-se citar ainda, 0 Algoritmo de Baynes, que podem através de variáveis distintas, manipular números aleatórios, como: k-ésimo vizinho mais próximo (KNN), técnica utilizada para regressão e classificação de dados; e a Principal Component Analysis (PCA), que é utilizado para reduzir grandes conjuntos de dados. Esse é o contexto no qual a CGU promoveu a utilização de TICs na detecção de fraudes no Brasil, em que, passa-se a descrever como se desencadeou esse processo (Bao et al., 2020; Sundarkumar, Ravi \& Siddershwar, 2015).

A utilização das TICs no âmbito público iniciou-se na década de 60, através de empresas estatais, onde promoveram estruturas para o processo de informatização nas atividades governamentais. Mas, foi a partir dos anos 90 , que a disseminação do processo tecnológico se propagou, com a proliferação de serviços eletrônicos. 0 termo governo eletrônico (e-Gov), surgiu no Brasil em 2000, em que, restringiam-se ao fornecimento de serviços eletrônicos, nos portais de transparência. Evidenciou-se em 1994, o surgimento do Programa de Modernização da Administração Pública e o Programa de Desenvolvimento Informático, como marcos no desencadeamento de TICs no setor público brasileiro (Balsa, 2017; Gil-Garcia \& Lanza, 2015).

0 processo de inovação no controle à corrupção foi tema do fórum 'o controle no combate à corrupção' realizado em Brasília em dezembro de 2019, onde seis representantes de diferentes áreas da CGU expuseram medidas que foram implementadas, com resultados satisfatórios, de acordo com os seus idealizadores (CGU, 2019). O painel apresentou cinco propostas utilizadas pela CGU: a malha fina dos convênios; a plataforma FalaBR; o observatório da prevenção; a mudança metodológica para os Processos Administrativos Disciplinares (PAD); e o Analisador de Licitações, Contratos e Editais (Alice) (CGU, 2019).

Diante da aplicação indevida de recursos públicos, os órgãos de controle, enfrentam gargalos no desempenho de suas atividades, ainda limitados pela número reduzidos de servidores e excessivo volume de 
convênios, de acordo com Rangel (2019), em abril/2019 apresentavam-se 12.838 convênios, totalizando um montante de $\mathrm{R} \$ 16.343 .176 .940,04$ (bilhões de reais), diante desse quadro a CGU, buscou alternativas para amenizar esse impasse, desenvolvendo TICs para atender a demanda de fiscalizações(Carvalho, 2020). Passa-se a destacar as principais TICs da CGU.

A CGU produziu a plataforma FalarBR, que proporciona aos cidadãos a solicitação de informações públicas e manifestações de ouvidoria, em conformidade com a LAl e o Código de Defesa dos Usuários de Serviços Públicos, o objetivo da iniciativa é facilitar a vida do cidadão, onde encontra, em um único portal, um gama de informações, seja para manifestações (e-Ouv) ou pedidos de acesso à informação (Bourges, 2020; CGU, 2019).

Outra, TIC apresentada pela CGU foi o observatório da prevenção da corrupção, evidencia-se como um canal de prestação de serviços e informações para a divulgação dos atos de corrupção, essa plataforma realiza suas ações através de quatro projetos: taxonomia da prevenção e combate; prevenção baseada em evidências; prevenção baseada em referências e o portal da Prevenção da Corrupção, destacando-se, como uma ação proativa no combate à corrupção (CGU, 2019).

Por sua vez, a CGU também desenvolveu uma nova metodologia para os Processos Administrativo Disciplinares (PAD), onde, o tempo de duração de um processo foi reduzido para seis meses, e a instauração dos processos só são abertos com convicção suficiente para serem concluídos, tornando-se mais ágil e econômico para o Governo Federal (CGU, 2020).

Por último, destaca-se a ferramenta 'Alice", tecnologia digital, que realiza análise permanente, de conteúdos, de forma antecedente, concomitante e subsequente de licitações no âmbito Federal, ações preventivas nesses processos são desenvolvidas, a partir do lançamento no Compras net, com foco principal nas necessidades do órgão, sobre volume, pesquisa de preços, e cláusulas restritivas para participação equitativa, esta ferramenta de 2018 a 2019, já promoveu benefícios de $\mathrm{R} \$ 4,3$ bilhões em auditorias preventivas (Panis, 2020; CGU, 2019). Através dessas ferramentas, utilizadas conjuntamente a CGU promove a fiscalização de recursos federais que foram repassados para os entes públicos no Brasil.

Para contextualizar esse estudo, nos interessa entender como está se provendo os atos de corrupção com os recursos disponibilizados para combater à Covid-19, tornou-se necessário o detalhamento acerca da estimativa do curto da corrupção com recursos da Covid-19, enfatizado a seguinte.

\subsection{Estimativa do custo da corrupção com recursos da Covid-19}

O ensino de contabilidade nas IES e a sua relação com o Exame de Suficiência foi abordada por Madeira, Mendonça e Abreu (2003) que destacam este como um indicador de qualidade para as respectivas instituições. Além de permitir a habilitação profissional, o Exame de Suficiência pode servir de apoio às IES no processo de avaliação e acompanhamento dos currículos, pois mediante os exames é possível verificar os conteúdos exigidos e compará-los com aqueles ministrados, permitindo identificar deficiências, 0 aprimoramento dos cursos e, consequentemente, reduzindo as reprovações (Madeira, Mendonça, \& Abreu, 2003).

Sobre a história da corrupção no Brasil, destaca-se, que as práticas ilegais no Brasil se iniciaram no período de colonização portuguesa, século XVI, onde funcionários públicos, que fiscalizavam o contrabando do pau-brasil e especiarias, passaram a exercer a prática ilegal desse comércio, ainda se atribui a herança ibérica e ao patrimonialismo, tipo de dominação política que já predominou no Brasil. Essa configuração da corrupção brasileira, está arraigada à cultura da política no Brasil, e através desta, tenta-se explicar a falta de zelo na aplicação das verbas públicas, essas ações são provenientes dos antecedentes históricos da nossa nação, e no século XXI, ainda continua atuante em vários setores da administração pública (Schwarcz, 2008). 
De acordo com estudo realizado pela Federação das Indústrias do Estado de São Paulo (FIESP), o custo da corrupção no Brasil, evidenciou-se de $\mathrm{R} \$ 69$ bilhões de reais/ano; esse fato poderia elevar a renda per capita do Brasil, para US $\$ 9$ mil dólares/ano, maior em 15,5\% do atual na época da pesquisa em 2008. Este estudo foi realizado pelo Departamento de Competitividade e Tecnologia (Decomtec) da FIESP, demonstrando os prejuízos que a corrupção causa a economia brasileira (FIESP, 2010).

A pesquisa da FIESP, apresentou o custo médio da corrupção, de cerca de 1,38\% a 2,3\% do Produto Interno Bruto (PIB), representando, $\mathrm{R} \$ 41,5$ bilhões a $\mathrm{R} \$ 69,1$ bilhões que são transacionados em atos de corrupção com verbas públicas. $O$ estudo ainda demonstra quanto o país poderia investir em áreas estratégicas, como educação, saúde e segurança, com esses recursos (FIESP, 2010).

Destaca-se internacionalmente, o Índice de Percepção de Corrupção (IPC), indicador que avalia o nível de corrupção do setor público dos países, idealizado pela Transparency International, criada em 1995. O índice é uma combinação de 13 pesquisas e avaliações de corrupção, coletadas por vários órgãos de renome. O IPC é considerado por especialistas e executivos de negócios, como o mais amplamente utilizado (Bataglia \& Farranha, 2020; Transparency International, 2020; Shalders, 2020). A metodologia segue quatro etapas básicas: seleção da fonte de dados, redimensionamento da fonte dados, agregando os dados redimensionados e, em seguida, relatando medidas de incerteza (Transparency International, 2020).

A classificação do Brasil no IPC da Transparency International é $94^{\circ}$ posição no ranking de 180 países, com um score de 35 pontos de 100, configurando-se um país com um índice baixo (ruim), para os critérios analisados pelo IPC, estando atrás de países, como Chile, Peru, Costa Rica, Senegal. Argentina, Tunísia e outros (Transparency International, 2020).

O Instituto Brasileiro de Planejamento Tributário (IBPT), também apresentou estudo sobre o custo da corrupção, em que, evidenciou-se que a corrupção consome $8 \%$ de tudo que é arrecadado no país, cerca de $\mathrm{R} \$ 160$ bilhões por ano. De acordo com o coordenador de estudos do IBPT, Gilberto Luiz Amaral, para se chegar a essa conclusão, o instituto considerou os desvios apurados pela operação Lava Jato e processos envolvendo corrupção no Tribunal de Contas da União (TCU) e nos Tribunais de Contas dos Estados (TCEs), ainda ressaltou que esses $8 \%$ representariam $\mathrm{R} \$ 139$ bilhões, que poderiam ser utilizados para amenizar os contingenciamentos em áreas estratégicas, como saúde e educação (IBPT, 2017).

Por sua vez, a Organização das Nações Unidas (ONU), realizou estudo que evidenciou o custo anual da corrupção no Brasil, que seria em 2016 de $\mathrm{R} \$ 200$ bilhões de reais, por ano, esse custo representa entre 4\% e 5\% do PIB brasileiro (Veloso, 2019; Revista Isto é, 2017). O coordenador da força tarefa da Operação Lava jato, Deltan Dallagnol, destacou que esses valores apontados no estudo da ONU, corresponde a três vezes o orçamento da educação e da saúde no Brasil (Bochewek \& Pereira, 2018; Dallagnol, 2017).

Com base nesses relatos, elaborou-se uma estimativa média de qual seria o custo da corrupção no Brasil, para se comparar com os valores detectados pelas TICs da CGU em recursos disponibilizados para combater à Covid-19. Apresentada na Tabela 1.

Tabela 1: Estimativa do Custo anual médio da Corrupção no Brasil

\begin{tabular}{|c|c|c|c|}
\hline Órgão/Entidade & Custo da Corrupção & Cálculo & PIB 2019 \\
\hline FIESP (2010) & $1,38 \%$ a $2,3 \%$ do PIB & $\begin{array}{c}\mathrm{R} \$ 7,3 \text { trilhões } \mathrm{X}(1,3 \%+2,3 \% / 2) \\
\text { (PIB/2019) }\end{array}$ & $\mathrm{R} \$$ 83.5 Bilhões \\
\hline ONU (2017) & $4 \%$ a $5 \%$ PIB & $\begin{array}{c}\mathrm{R} \$ 7,3 \text { trilhões } \mathrm{X}(4 \%) \\
(\mathrm{PIB} / 2019)\end{array}$ & $\mathrm{R} \$ 294$ bilhões \\
\hline IBPT (2017) & $\begin{array}{l}\text { 8\% da arrecadação } \\
\text { Nacional }\end{array}$ & $\begin{array}{l}\mathrm{R} \$ 1,467 \text { trilhões } \times 8 \% \\
\text { (Arrecadação Total) }\end{array}$ & $\mathrm{R} \$ 117$ bilhões \\
\hline \multicolumn{3}{|c|}{ Total } & R\$ 494,5 Bilhões/3 \\
\hline \multicolumn{3}{|c|}{ Custo Médio anual da Corrupção no Brasil } & $\mathrm{R} \$ 164,8$ bilhões \\
\hline
\end{tabular}

Fonte: FIESP (2010) e IBPT (2017). 
De acordo com a Tabela 1, a estimativa do custo corrupção pelas médias dos três indicadores, representaram cerca de $\mathrm{R} \$ 164,8$ bilhões de reais, esse montante seria o custo total anual da corrupção da utilização de todos dos recursos públicos no Brasil, como os recursos disponibilizados para à Covid-19, corresponderam a 12,78\% dos recursos públicos em 2020, então, apresenta-se na Tabela 2, o custo da corrupção para com os recursos da Covid-19 em 2020.

Tabela 2: Estimativa do cálculo do custo da corrupção com recursos da covid-19.

\begin{tabular}{|c|c|}
\hline Informações Covid-19 (2020) & Cálculos do custo da corrupção \\
\hline Recursos Federais Disponibilizados à Covid-19 & $\begin{array}{l}\mathrm{R} \$ 457 \text { Bilhões de reais (Portal da transparência Gov. Federal } \\
(2020)\end{array}$ \\
\hline $\begin{array}{l}\text { Esses recursos disponibilizados de } \\
\mathrm{R} \$ 457 \text { bilhões }\end{array}$ & $\begin{array}{c}\text { Representam } 12,78 \% \text { dos recursos públicos disponibilizados em } \\
2020 \text { para combater à covid- } 19\end{array}$ \\
\hline $\begin{array}{l}\text { Estimativa do custo da corrupção com recursos à Covid-19 } \\
\text { de acordo com metodologia do IBPT/FIESP/ONU }\end{array}$ & $\begin{array}{c}\mathrm{R} \$ 164,8 \text { bilhões (custo total) } \mathrm{X} 12,78 \% \text { (Representação de } \\
\text { recursos à Covid-19= R } \$ 21,06 \text { bilhões de reais }\end{array}$ \\
\hline $\begin{array}{l}\text { Estimativa pelos estudos para o custo da corrupção com } \\
\text { recursos à Covid-19 }\end{array}$ & $R \$ 21,06$ bilhões de reais \\
\hline
\end{tabular}

Fonte: Elaborada pelos Autores (2020).

A estimativa do custo da corrupção para com os recursos disponibilizados para combater a pandemia à Covid-19, de acordo a tabela 2, representam cerca de $R \$ 21,06$ bilhões de reais, objetivou-se essa estimativa para comparar com os valores detectados pelas TICs da CGU, com a estimativa projetada para o custo da corrupção com verbas destinadas a pandemia.

\subsection{0 desenvolvimento da Fraude}

A fraude pode ser considerada como uma deturpação deliberada, ocultação e negligência de uma verdade para manipulação de relatórios financeiros, à custa da instituição (Abdullahi \& Mansor, 2015). Ainda de acordo com Ernst e Young (2009) define fraude como um ato de ação deliberada feita por uma entidade ou indivíduo, sabendo que tal ação pode resultar na posse de benefícios ilegais, para alcançar benefícios pessoais.

Com o objetivo de entender a motivação da fraude, com os indivíduos no ambiente organizacional, Donald R. Cressey em 1953, idealizou o triângulo da fraude, o qual é representado na perspectiva do fraudador, composto de três elementos: pressão, racionalização e oportunidade. 0 primeiro, pressão de realizar 0 ato, geralmente está relacionada com um problema financeiro, de acordo com Abdullahi \& Mansor (2015), exemplos de pressão percebida, incluem, ganância, alto padrão de vida, dividas pessoais, problemas financeiros, toxicodependência e jogos de azar, por sua vez, Murdock (2008), argumenta que a pressão pode estar relacionada a fatores financeiros, não financeiros, políticos e sociais, em que uma pessoa sente e acredita que não pode falhar devido ao seu status ou reputação.

O segundo fator, a racionalização, é a razão que levou a cometer 0 ato desonesto, este conceito indica que o perpetrador deve formular alguma ideia moralmente aceitável, antes de se envolver em comportamento antiético; refere-se à justificativa e desculpas de que a conduta imoral difere da atividade criminosa, sendo uma justificativa de comportamento fraudulento devido à falta de integridade pessoal, ou raciocínio moral (Abdullahi \& Mansor, 2015; Rae \& Subramanyan, 2008).

Por último, para a ocorrência da fraude, destaca-se, a oportunidade percebida, que é criada pela ineficácia dos controles internos ou sistema de governança frágil, que propiciam ambiente favorável para que um indivíduo cometa a fraude organizacional, sendo o fator que pode ser alterado pela ação institucional, pois, depende do aprimoramento dos controles internos (Rocha, 2018, brasiliano, 2015; Abdullahi \& Mansor, 2015).

$\mathrm{Na}$ continuidade desses estudos, Wolfe e Hermanson (2004) desenvolveram o 'diamante da fraude' em que, aprimoraram o modelo do triângulo da fraude, acrescentando a variável, 'capacidade do indivíduo em 
cometer a fraude', destacando-se como a questão central desse modelo, as características observáveis nos indivíduos, que os levam a cometer a fraude, como: posição de autoridade que ocupa, capacidade de entender e controlar sistemas contábeis, e conhecer as fraquezas dos controles internos (Peres \& Brizoti, 2016).

$\mathrm{Na}$ continuidade des estudos relacionados com a fraude, em 2016, Renato Santos, inseriu novo elemento no diamante da fraude, transformando no 'pentágono da fraude', conforme Figura 1.

A esse novo modelo foi acrescentada a variável, 'a disposição ao risco'. Os modelos idealizados objetivaram entender as motivações da fraude organizacional, constata-se que ocorreram evoluções no modelo do triângulo da fraude (1953), mas destaca-se que o fator principal a ser monitorado nas organizações, contínua sendo a 'oportunidade' (Brasiliano, 2018; Abdullahi \& Mansor, 2015).

Figura 1: Pentágono da Fraude

\section{Racionalização}

\section{Oportunidade}

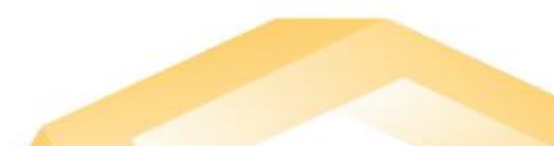

Capacidade

Pressão

Fonte: Santos (2016).

Destaca-se a relação custo-benefício, como fator relevante que é considerado pelo fraudador, pois, esse irá analisar as possibilidades de sucesso dos seus atos, nessa ótica Szwajkowski (1985), observa que o fraudador realizará três categorias de análises: risco - perigo (são experiências negativas); risco - possibilidade (quantificação do risco) e risco - aventura (positividade da aventura), evidencia-se que a propensão ao risco não é somente uma variável de investidores do mercado de capitais, pois, na busca pela produção de riquezas a qualquer custo, observa-se a promoção de riscos para atos fraudulentos pelos indivíduos nos ambientes organizacionais (Santos, 2016).

\subsection{Estudos Anteriores}

No estudo realizado por Paschoal, Santos e Faroni (2020), objetivaram a classificação e identificação de irregularidades nos relatórios de auditoria da CGU, onde através do triângulo e diamante da fraude, podese explicar os mecanismos de atos fraudulentos na administração pública municipal brasileira, destacando-se a oportunidade, como a principal variável no cometimento da fraude, pois, está relacionada com as falhas no controle interno, ainda se destacou a 'capacidade', onde o cargo ocupado pelo indivíduo pode influenciar à ação dolosa e as variáveis pressão e racionalização foram observadas em menor evidência nessas análises.

$\mathrm{Na}$ pesquisa desenvolvida por Bataglia e Farranha (2020) buscaram a verificação da relação entre prevenção e controle de atos corruptos, por meio das tecnologias disponíveis e institucionalizadas pela CGU. Constatou-se que a correlação, prevenção e controle de corrupção, não é direta, pela existência de outras variáveis que influenciam esses aspectos. Os resultados navegaram por meio do debate entre os aspectos culturais, Lei de Acesso à Informação (LAI), controle social e governança pública. 
No estudo de Panis (2020) analisou-se a Tecnologia de controle de Editais e Licitações 'Alice', como ferramenta de combate a corrupção pela CGU. Demonstrou que a ferramenta auxilia a CGU no controle de irregularidades nos processos licitatórios no Brasil. Na utilização do modelo Gestão Pública Inovadora (GESPUBLIN), framework elaborado para aplicação no contexto brasileiro, no poder executivo federal, evidenciou-se positiva a implantação da ferramenta 'Alice' no setor público.

O estudo de Caldas, Costa e Pagliarussi (2015) analisaram a relação entre os gastos públicos e a corrupção no Brasil. Constatou-se uma relação robusta entre gastos públicos e corrupção, principalmente pelo poder discricionário da despesa pública nos municípios brasileiros.

Os estudos anteriores relacionados com o tema, apontam para a necessidade de implementação de controles efetivos, para reduzir os atos de corrupção na gestão pública, como principais canais de descobrimento da fraude, apresentaram-se os canais de denúncias, sejam as oficiais ou anônimos, e destacaram-se as TICs como instrumento eficaz na constatação de irregularidades nos processos governamentais (Paschoal, Santos \& Faroni, 2020; Bataglia \& Farranha, 2020; Panis, 2020; Caldas, Costa \& Pagliarussi, 2015).

\section{Procedimentos Metodológicos}

A pesquisa quanto ao seu objetivo é descritiva, onde se almeja descrever as características de uma população ou fenômeno e as relações entre esses. Com relação aos procedimentos técnicos, evidenciam-se documentais, pois, foram analisados websites do Governo Federal, da Controladoria Geral da União, polícia Federal do Brasil e da agência Nacional, na busca de informações para subsidiar este estudo (Gil, 2010; Marconi \& Lakatos, 2009; Beuren, 2006).

A forma de abordagem configurou-se qualitativa, pois, considera que existe uma relação entre o mundo real e o sujeito que não pode ser traduzida em números, onde a interpretação dos fenômenos é a base da pesquisa qualitativa, que descreve os achados do pesquisador. $O$ tratamento de dados desenvolveu-se através da análise de conteúdo, promovendo a interpretação dos dados com inferência dos autores (Gil, 2010, Marconi \& Bardin, 2011; Lakatos, 2009; Beuren, 2006).

Sobre as técnicas de pesquisas, a obtenção e compilação dos dados, deu-se através da análise de documentos, onde os dados foram capturados no período de 5 maio de 2020 a 12 novembro de 2020, e ainda se realizou a análise de conteúdo, que busca a exploração dos textos e tratamento dos resultados, promover interpretações e inferências sobre o objeto de estudo (Bardin, 2011).

Esse arcabouço metodológico teve por objetivo analisar a eficácia das TICs utilizadas pela CGU, para combater fraudes com os recursos públicos que foram disponibilizados pelo Governo Federal para os entes federativos no combate a pandemia da Covid-19, nas compras e aquisições de serviços para reduzir a ação do coronavírus na população brasileira, assim como as demais políticas públicas desenvolvidas com esse objetivo.

$\mathrm{Na}$ presente pesquisa seguiram-se as seguintes etapas: 1) evidenciação de atos de corrupção e fraudes em licitações públicas, detectadas pela CGU, através de ferramentas tecnológicas; 2) comparação das detecções de ilícitos, com os montantes liberados, para verificar a efetividade dessas ferramentas, através de parâmetros de corrupção estabelecidos por indicadores como: FIESP, ONU, IBPT e OKBR.

Para se verificar a efetividade das TICs da CGU, utilizaram-se os parâmetros estabelecidos pelas entidades, Federação das Indústrias do Estado de São Paulo (FIESP) (2010), Instituto Brasileiro de Planejamento Tributário (IBPT) (2017) e Organização das Nações Unidas (ONU) (2017). No tópico deste estudo estimativa do cálculo do custo da corrupção, foi estabelecido o valor de $\mathrm{R} \$ 21,06$ bilhões de reais, em que se projetou como o parâmetro para os desvios de recursos disponibilizados para a pandemia da Covid-19, em que, foi comparado com as constatações de irregularidades detectadas pela CGU e demais órgãos de controle. 


\section{Análise e Discussão dos Resultados}

O governo federal para combater a pandemia à Covid-19, desencadeou diversos programas para atender as necessidades emergenciais dos entes federativos, Distrito Federal, Estados e Municípios, como pode ser observado na Tabela 3.

Tabela 3: Recursos Disponibilizados - Governo Federal na Pandemia da Covid-19

\begin{tabular}{|c|c|c|}
\hline Detalhamento da Despesa & Valor & $\%$ \\
\hline Auxílio Emergencial & $254.200 .000 .000,00$ & $55,52 \%$ \\
\hline Auxílio Financeiro aos (M. E Interna DF) & $60.189 .488 .452,00$ & $13,14 \%$ \\
\hline Benefício emergencial de manutenção do emprego e renda & $43.700 .472 .937,37$ & $9,54 \%$ \\
\hline Demais programas no combate a pandemia da Covid-19 & $99.873 .695 .203,00$ & $21,80 \%$ \\
\hline Total & 457.963.656.592,91 & $100 \%$ \\
\hline
\end{tabular}

Fonte: Portal da Transparência (2020).

De acordo com a Tabela 3, foram disponibilizados até novembro de 2020, $\mathrm{R} \$ 457$ bilhões de reais, que corresponde a $12,78 \%$ dos gastos públicos, com recursos disponibilizados pelo governo Federal no combate à Covid-19, desse total $\mathrm{R} \$ 410$ bilhões já foram liquidados e $\mathrm{R} \$ 409$ bilhões de reais pagos, destacase que $55,52 \%$ dos recursos foram empregados no auxílio emergencial, onde já foram pagos $R \$ 254$ bilhões de reais aos brasileiros que se encontram em situação de vulnerabilidade social, mas evidenciou-se que ações da CGU e com outros órgãos federativos conseguiram através das TICs detectar indícios de fraudes que ocorreram na pandemia (CGU, 2020).

No Gráfico 1 apresentam-se os montantes de verbas federais que foram transferidas para os Estados para suprir carências de arrecadação Estadual e atender programas de combate à Covid-19.

Gráfico 1: Verbas Federais transferidas para os Estados brasileiros

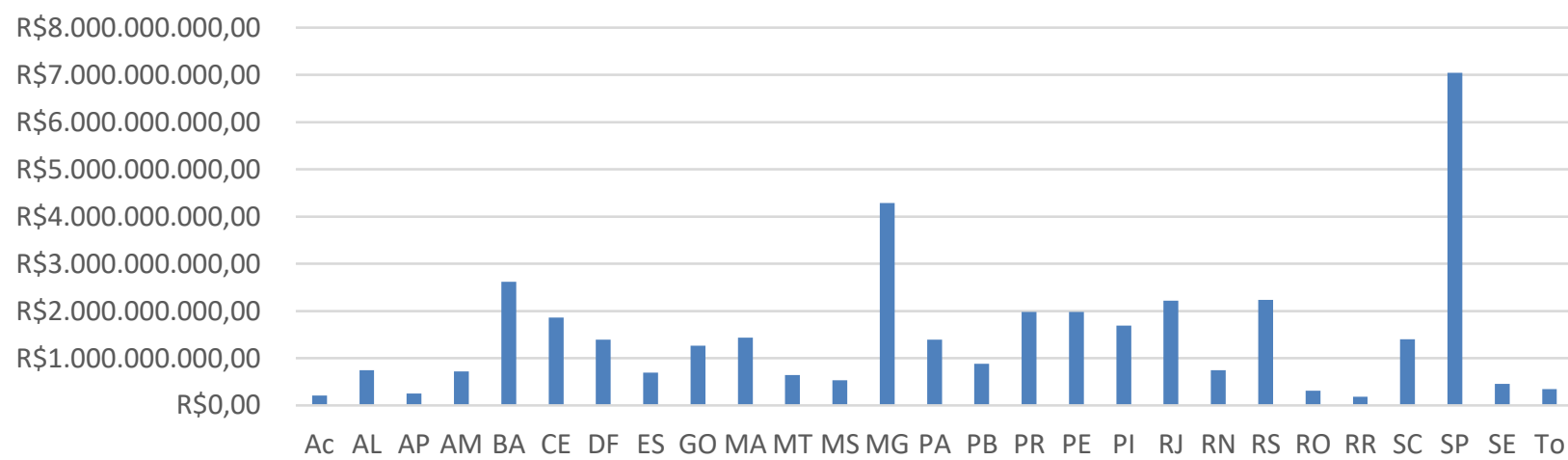

Fonte: CGU (2020)

De acordo com o gráfico 1, observa-se que o Estado que recebeu o aporte representativo de recursos, foi São Paulo, com R \$ 7,04 Bilhões de reais, Minas Gerais, com R \$ 4,2 bilhões e Bahia, com R\$ 2,6 bilhões; no que the concerne, os Estados com menor aporte foram: Roraima com, $\mathrm{R} \$ 182$ milhões de reais, Amapá, com $R \$ 252$ milhões de reais e Rondônia, com $R \$ 310$ milhões de reais. O projeto de Lei Parlamentar (PLP) $n^{0}$ 149/2019, concedeu auxílio emergencial para Estados e municípios para suprir queda de arrecadação de Impostos sobre Circulação de Mercadorias e Serviços (ICMS) e Imposto sobre Serviços de qualquer natureza (ISS). 
No Gráfico 2 apresentam-se as verbas do auxílio emergencial que foram disponibilizadas aos brasileiros em vulnerabilidade social, por decorrência da pandemia da Covid-19, que ficaram sem renda, por ocasião do fechamento do comércio e demais atividades, para amenizar o contágio do coronavírus (Nander, 2020; CGU, 2020).

Gráfico 2: Valores pagos por Estado do Auxílio emergencial

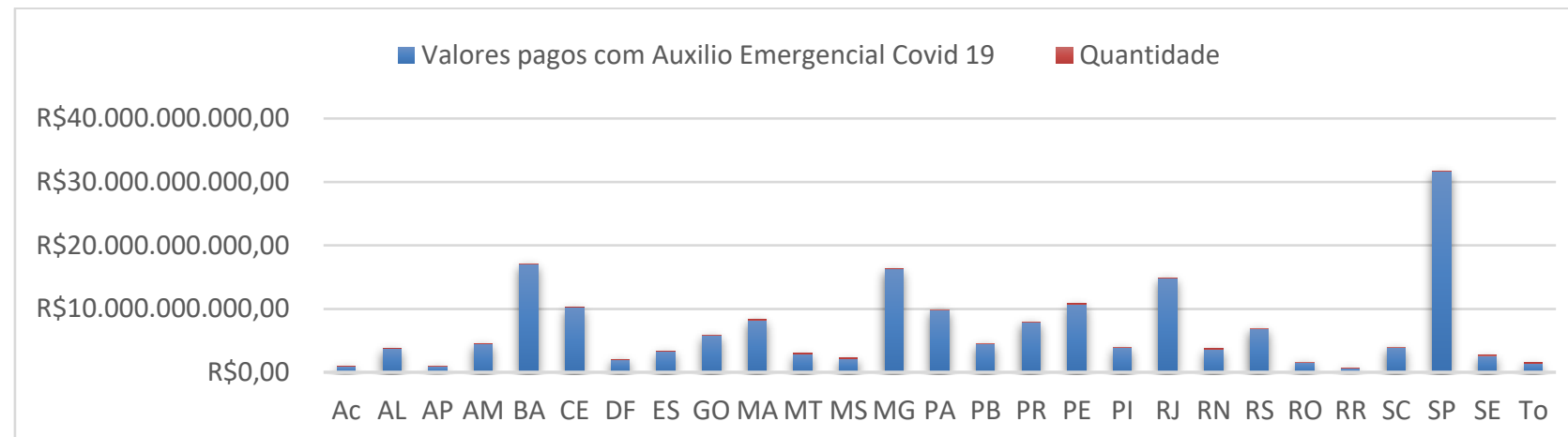

Fonte: CGU (2020)

$\mathrm{Na}$ análise do gráfico 2, constatou-se que os Estados que receberam os maiores montantes de pagamentos do auxílio emergencial foram: São Paulo, Bahia, Minas Gerais e Rio de Janeiro, com valores respectivos de $\mathrm{R} \$ 31,68$ bilhões, $\mathrm{R} \$ 17,03$ bilhões, $\mathrm{R} \$ 16,28$ bilhões e $\mathrm{R} \$ 14,82$ bilhões de reais. Por conseguinte, os menores montantes foram: Roraima, Tocantins, Rondônia e Distrito Federal, com valores respectivos de $R \$ 647$ milhões de reais, $R \$ 1,46$ bolhões e $R \$ 1,94$ bilhões de reais (CGU, 2020).

As informações para estudo foram buscadas nas páginas da CGU e da Polícia Federal, sobre ilícitos praticados pelos entes federativos e com servidores públicos, com recursos para combater a pandemia da Covid-19, em que se passa a analisar a efetividade das TICs utilizadas pela CGU.

De acordo com a CGU (2020), cerca de 680 mil servidores das três esferas de Poder (municipal, estadual e Federal), receberam cerca de $\mathrm{R} \$ 1$ bilhão de reais, indevidamente do programa de auxílio emergencial, que objetiva amenizar os impactos da pandemia da Covid-19, destaca-se que esse benefício se destina as pessoas em situação de vulnerabilidade social, como desempregados, microempreendedores, trabalhadores informais e outros, dessa forma não se destinando a servidores públicos como preconiza a Lei $n^{0} 13.982 / 2020$ (Nander, 2020)

As constatações dos ilícitos foram detectadas pela CGU no cruzamento de informações da base de dados do benefício com outras bases, através dos Cadastro Pessoa Física (CPF) desses agentes públicos, em cooperação com os Tribunais de Contas Estaduais (TCEs) das 27 unidades federativas do Brasil (CGU, 2020). Apresentam-se nas Tabelas 4 e 5 um resumo dos servidores públicos e os montantes recebidos pelos mesmos do auxílio emergencial. Na Tabela 4 apresentam-se os valores que foram pagos a servidores federais do auxílio emergencial, conforme CGU (2020).

Tabela 4: Servidores públicos federais que receberam auxílio emergencial

\begin{tabular}{ccccc}
\hline Situação do Vínculo & Quantidade de & Quantidade de & \multicolumn{2}{c}{ Valor Pago } \\
Beneficiários & Parcelas pagas & (R\$) & $\%$ \\
Civil com vínculo no SIAPE & 14.182 & 26.509 & $16.852 .200,00$ & $29 \%$ \\
Militar da União, ativo ou inativo & 52.001 & 63.700 & $39.454 .200,00$ & $68 \%$ \\
Funcionário de empresa Estatal Federal & 950 & 2.231 & $1.505 .400,00$ & $3 \%$ \\
Total & $\mathbf{6 7 . 1 3 3}$ & $\mathbf{9 2 . 4 4 0 , 0 0}$ & $\mathbf{5 7 . 8 1 1 . 8 0 0 , 0 0}$ & $\mathbf{1 0 0 \%}$ \\
\hline
\end{tabular}

Fonte: Controladoria Geral da União (2020). 
Como se observa na Tabela 4, entre os servidores públicos federais o vínculo com destaque de maior incidência de irregularidades, no recebimento do auxílio emergencial se promoveu entre os militares da União, ativos, inativos ou pensionistas, com $68 \%$ de constatações pela CGU. Por sua vez, o aporte representativo de $\mathrm{R} \$ 923$ milhões se processou entre os servidores das outras esferas de poder, conforme Gráfico 3.

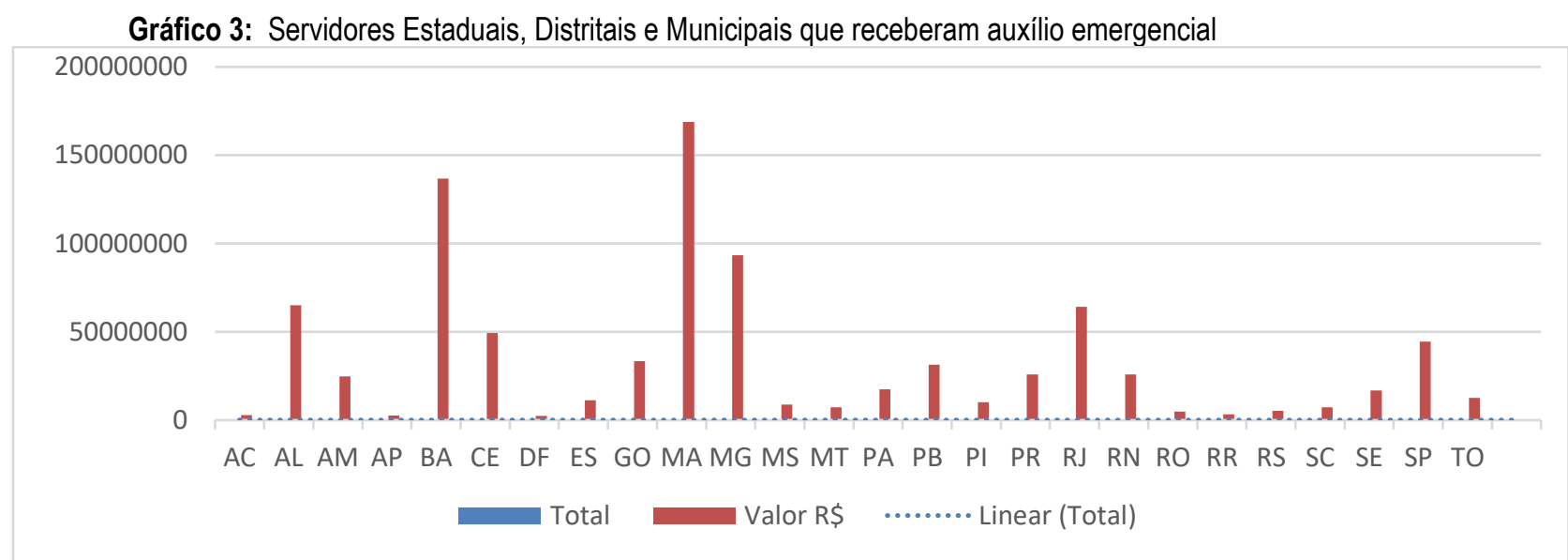

Fonte: CGU (2020)

$\mathrm{Na}$ análise do Gráfico 3, constata-se que os Estados com destaque na incidência de recebimento indevido do auxílio emergencial, foram os Estados, Maranhão, com R $\$ 168.808 .800$ (18,27\%), Bahia, com R\$ 136.725.600 (14,99\%), Minas Gerais, com R\$ 93.427 .200 (10,11\%), observa-se que essas detecções se realizaram através de ação conjunta da CGU e TCE dos Estados da Federação. De acordo com Nander (2020), este fato pode estar relacionado, as regiões Norte e Nordeste terem aderido ao programa com uma parcela significativa da população, como Amapá e Maranhão, com 45\% e 65\% respectivamente, regiões de incidência de vulnerabilidade social, justificando a elevada incidência (CGU, 2020).

Destaca-se que até novembro de 2020, 65 milhões de brasileiros, foram beneficiados com $\mathrm{R} \$ 254$ bilhões de reais de aportes para os participantes do auxílio emergencial, os servidores públicos com recebimento irregular desse benefício representam $0,42 \%$ ( 1 bilhão de reais) do montante efetivamente pago aos beneficiários regulares, mas, evidencia-se que as TICs utilizadas pela CGU, foram eficazes na detecção dessas irregularidades no tocante aos servidores públicos (Nander, 2020; CGU, 2020).

Dessa forma, às três teorias que estudam a fraude, através das metodologias do, triângulo da fraude, o diamante da fraude e o pentágono da fraude, evidenciam que a principal variável a ser monitorada, está sob o controle da instituição, destacando-se a 'oportunidade', a ação da CGU foi fundamental para inibir a ação de outros servidores públicos intentassem a buscar 0 auxílio emergencial, pois, a detecção das irregularidades inibiram o intento de outros que planejavam buscar o benefício social (Rocha, 2018; Peres \& Brizoti, 2016, Brasiliano, 2015).

Coadunam com esse entendimento o estudo realizado por Paschoal, Santos e Faroni (2020), que em pesquisa sobre fraudes detectadas pela Auditoria da União, a oportunidade, destacou-se representativa na incidência sobre as demais variáveis, pela fragilidade detectadas pelos fraudadores nos controles internos, como motivador para o cometimento do ato fraudulento.

Com relação as demais pessoas que receberam o auxílio emergencial indevidamente o Tribunal de Contas da União (TCU), informou que 3,7 milhões de beneficiários pagos, foram cancelados, o que gerou uma economia de $\mathrm{R} \$ 8.8$ bilhões de reais aos cofres públicos, esses estão em processo de devolução dos valores, mas destaca-se que somente $5 \%$ ressarciram os cofres públicos (Nander, 2020; CGU, 2020). 
Destarte, passa-se a analisar as principais ações da CGU, investigadas pela Polícia Federal que geraram 'operações' para combater atos de corrupção na pandemia da Covid-19. Evidencia-se no quadro 2 as principais operações desencadeadas pela polícia Federal.

Quadro 2: Operações realizadas pela política Federal na pandemia da covid-19

\begin{tabular}{|c|c|c|c|c|}
\hline Operação & Cidade-Estado & Data & Situação de Fato & Valores \\
\hline $\begin{array}{l}\text { Cobiça } \\
\text { Fatal }\end{array}$ & $\begin{array}{l}\text { São Luis- MA e } \\
\text { São José do } \\
\text { Ribamar - MA } \\
\text { Aracajú- SE e }\end{array}$ & 09/06/2020 & $\begin{array}{c}\text { Fraudes em Licitações e desvio de verbas } \\
\text { Federais utilizados na pandemia da Covid-19- } \\
\text { superfaturamento de } 341 \% \\
\text { Desvio de verbas públicas no funcionamento do }\end{array}$ & 2,3 Milhões \\
\hline Serôdio & $\begin{array}{l}\text { Nossa Senhora } \\
\text { do Socorro-SE }\end{array}$ & 07/07/2020 & $\begin{array}{l}\text { Hospital de Campanha de Aracaju/SE. } \\
\text { Descumprimento do termo de referência; }\end{array}$ & 3,2 milhões \\
\hline Panacela & Oiapoque-AP & $14 / 06 / 2020$ & $\begin{array}{l}\text { combate desvio de medicamentos e de teste de } \\
\text { diagnósticos para Covid-19, além do uso indevido } \\
\text { de serviços públicos de saúde }\end{array}$ & Não declarado \\
\hline $\begin{array}{l}\text { Operação } \\
\text { Fiel da } \\
\text { Balança }\end{array}$ & Macapá-AP & 08/07/2020 & $\begin{array}{l}\text { objetivo de apurar fraude em licitação realizada } \\
\text { com recursos federais destinados ao } \\
\text { enfrentamento à Covid-19, em Macapá/AP. }\end{array}$ & Não declarado \\
\hline $\begin{array}{l}\text { Vírus } \\
\text { Infectio }\end{array}$ & Amapá & $26 / 06 / 2020$ & $\begin{array}{c}\text { desarticular organização criminosa que pratica } \\
\text { crimes de fraude em licitação e corrupção, com } \\
\text { desvio de recursos públicos utilizados no } \\
\text { enfrentamento ao coronavírus, no estado do } \\
\text { Amapá. }\end{array}$ & 4,9 milhões \\
\hline Reagente & $\begin{array}{l}\text { Picos-Pl } \\
\text { Bom Jesus e } \\
\text { Uruçuí }\end{array}$ & 0207/2020 & $\begin{array}{c}\text { para investigar fraudes em licitação de compra de } \\
\text { testes da Covid-19, realizada pela prefeitura de } \\
\text { Picos/PI. }\end{array}$ & Não declarado \\
\hline Desvid-19 & Boa Vista- RO & $14 / 10 / 2020$ & $\begin{array}{c}\text { Apurar suspeitas de sobrepreço e } \\
\text { superfaturamento na execução de emendas } \\
\text { parlamentares destinadas ao combate à pandemia } \\
\text { em Roraima }\end{array}$ & 20 milhões \\
\hline
\end{tabular}

Fonte: Polícia Federal (2020)

Conforme quadro 2, destaca-se a região Norte do Brasil, com quatro operações (Oiapoque-AP; Macapá-AP; Amapá; Boa Vista-RO), realizadas pela polícia federal, na investigação de utilização fraudulenta de recursos Federais para o combate do coronavírus, por crimes contra a administração pública, com atos de licitação criminosa, com valores apontados nas investigações de cerca de $\mathrm{R} \$ 30$ milhões, somente na região Norte (Nader, 2020, Polícia Federal, 2020, CGU, 2020).

Constata-se que essas operações se iniciaram pela CGU e Auditoria Geral da União, por meio da ferramenta 'Alice', que promoveram as análises das licitações, contratos e editais com recursos, federais, em que, participaram dessas operações os tribunais de conta estaduais (TCE), o Departamento de Auditoria do SUS (DENASUS) e a polícia Federal, onde se detectaram atos de improbidade e corrupção ativa e passiva de cerca de R\$ 100 milhões de reais (Quadro 2) (Agência Brasil, 2020, Polícia Federal, 2020; CGU, 2020).

Na pesquisa realizada por Panis (2020), sobre a ferramenta 'Alice', utilizada na Gespublin, a mesma mostrou-se eficaz na constatação de irregularidades em licitações públicas realizadas no Brasil, com ações antecedentes, que a Auditoria da União impediu a abertura de processos licitatórios pela existência de vícios nos editais, promovendo a economicidade dos recursos públicos.

Dessa forma, outras investigações estão sendo realizadas pela polícia Federal, polícia civil e Ministério Público estaduais, que investigam indícios de fraudes que se aproximam de $R \$ 1,4$ bilhões de reais, valor que ultrapassa em 13 vezes a 'máfia dos sanguessugas' que ocorreu em 2006, com valores de R\$110 milhões de reais; os principais estados investigados são: São Paulo (R\$ 550 milhões); Rio de Janeiro (R\$ 770 milhões); Santa Catarina (R\$ 33 milhões); Ceará (R\$ 35 milhões); Amazonas (R\$ 7 milhões) e outros estados da 
federação, as principais ocorrências se referem a superfaturamento de respiradores e de hospitais de campanha (Estado de Minas, 2020, CGU, 2020).

Destaca-se que apesar dessas operações e prisões, com desvio de recursos públicos de 100 milhões em operações deflagadas e investigações de R 1,4 bilhões que estão em andamento na contenção da pandemia da Covid-19, entende-se estarem correlacionadas, com posição que o Brasil ocupa no IPC, em que, adota a escala de 0 a 100, na edição de 2019, onde Brasil obteve a nota 35, a mesma de 2018 (Shalders, 2020).

Na busca de subsídios para amparar esse índice de corrupção, o Instituto Brasileiro de Planejamento Tributário (IBPT), destacou que o brasileiro trabalha até 29 dias por ano, para cobrir os desvios com corrupção na administração pública, evidencia-se ainda, que a corrupção consome $8 \%$ de tudo que é arrecadado no país, R $\$ 160$ bilhões de reais, por ano (IBPT, 2017). Por sua, vez a ONU (2017), que estabeleceu a corrupção no Brasil em 2016 de $\mathrm{R} \$ 200$ milhões de reais, destacou que em irregularidades evidenciadas pela Petrobrás, representaram cerca de $\mathrm{R} \$ 40$ bilhões em fraudes contratuais (Veloso, 2019).

Isso nos remete que as constatações evidenciadas nas operações de controle de recursos públicos, encabeçadas pela CGU e demais órgãos fiscalizadores, depreende-se diante desse quadro de corrupção apontados pela FIESP, ONU, IBPT e OKBR que coadunam com a pesquisa de Caldas, Costa e Pagliarussi (2015) que constataram ser robusta a relação entre corrupção e gastos públicos.

Dessa forma, para se verifica a efetividade das ferramentas da CGU, no tocante as detecções, passase a fazer a racionalização para entender-se esse fato, observa-se a Tabela 5, os valores indevidos que foram detectados pelas TICs da CGU e outras entidades.

Tabela 5: Aplicações irregulares de recursos no combate à Covid-19

\begin{tabular}{|c|c|c|c|}
\hline Fonte da Irregularidade & Quantitativo & Montante R\$ & $\%$ \\
\hline Servidores públicos Federais (auxílio emergencial) & 92.440 & $57.811 .800,00$ & $0,51 \%$ \\
\hline $\begin{array}{l}\text { Servidores públicos (Estaduais, Municipais e Distritais - } \\
\text { auxílio emergencial }\end{array}$ & 613.431 & $923.901 .000,00$ & $8,19 \%$ \\
\hline $\begin{array}{c}\text { Demais cidadãos que receberam indevidamente } 0 \\
\text { auxílio emergencial }\end{array}$ & 3.700 .000 & $8.800 .000 .000,00$ & $78 \%$ \\
\hline Operações realizada pelo CGU e polícia Federal & 7 operações & $100.000 .000,00$ & $0,89 \%$ \\
\hline $\begin{array}{l}\text { Investigações em andamento sobre recursos } \\
\text { disponibilizados para combater à Covid-19 }\end{array}$ & $\begin{array}{l}5 \text { estados da } \\
\text { Federação }\end{array}$ & $1.400 .000 .000,00$ & $12,41 \%$ \\
\hline \multicolumn{2}{|l|}{ Total } & 11.281 .712 .800 & $100 \%$ \\
\hline
\end{tabular}

Fonte: CGU (2020)

De acordo com o cálculo do custo da corrupção evidenciado nas Tabelas 1 e 2, em que, dos recursos disponibilizados à Covid-19, cerca de $\mathrm{R} \$ 457$ bilhões de reais, depreende-se que 12,78\%, isto é, cerca de $\mathrm{R} \$$ 21,06 bilhões de reais, podem estar envoltos em atos de corrupção sejam de natureza ativa ou passiva.

Assim após pesquisas nos sites da CGU (Portal da Transparência), construiu-se a Tabela 6, em que, evidenciou-se em ações realizadas pela CGU, com suas TICs, conseguiram detectar cerca de R $\$ 11,28$ bilhões de reais de irregularidades com recursos da Covid-19; o parâmetro que se utilizou para verificar a efetividade das ferramentas da CGU, foi elaborado em tópico específico nesse estudo, onde representou cerca de $\mathrm{R} \$ 21,06$ bilhões de reais; destaca-se por essa ótica que a CGU conseguiu alcançar $53 \%$ dessa previsão, sendo um valor aproximado, em que pode haver variações.

Dessarte, infere-se que as TICs utilizadas pela CGU para monitorar e detectar fraudes foram funcionais, com resultados satisfatórios, pois, conseguiram alcançar um patamar representativo de ilícitos praticados com 
esses recursos, destaca-se que as investigações continuam e nos próximos anos esses valores serão atualizados (Agência Brasil, 2020; Brasil, 2020; IBPT, 2019).

A controladoria Geral da União, na atuação do monitoramento e controle das ações dos entes federados e instituições públicas, e no acompanhamento de programas do Governo Federal, obteve uma economia $\mathrm{R} \$ 42,73$ bilhões nos últimos oito anos como se observa na Tabela 6.

Tabela 6: Benefícios Financeiros apurados pela CGU por ano

\begin{tabular}{c|c|c|c|c|c|c|c|c|c}
\hline Benefícios & $\mathbf{2 0 1 2}$ & $\mathbf{2 0 1 3}$ & $\mathbf{2 0 1 4}$ & $\mathbf{2 0 1 5}$ & $\mathbf{2 0 1 6}$ & $\mathbf{2 0 1 7}$ & $\mathbf{2 0 1 8}$ & $\mathbf{2 0 1 9}$ & Total \\
\hline $\begin{array}{c}\text { Total } \\
\text { Bilhões de } \\
\text { reais }\end{array}$ & 2.33 & 2.74 & 7.54 & 2.87 & 2.87 & 4.61 & 7.29 & 12.94 & 42.73 \\
\hline
\end{tabular}

Fonte: CGU (2020)

De acordo com os resultados apresentados pela CGU (2020), onde se obteve benefícios financeiros, através da sua sistemática de controle interno, em que, destacam-se, o cancelamento de licitações e contratos com objeto desnecessário, com economia de $\mathrm{R} \$ 1,59$ bilhões, suspensão de pagamento não continuado (indevido), em 17,33 bilhões, recuperação de valores pagos indevidamente, com $\mathrm{R} \$ 1,79$ bilhões, dentre outras ações realizadas pela CGU e demais órgãos fiscalizadores sob o seu comando.

Observa-se que a CGU, antes da pandemia da Covid-19 já realizava ações preventivas no monitoramento dos recursos federais, a projeção para o ano de 2020, de acordo com a tabela 6 , seriam de cerca de $\mathrm{R} \$ 13$ bilhões de benefícios (economicidade) para o total de recursos federais liberados. Conforme demonstrado na Tabela 5 , entre os ilícitos praticados somente com recursos disponibilizados para combater à Covid-19, detectou-se cerca de $\mathrm{R} \$ 11,2$ bilhões de reais de irregularidades constatados pela CGU, promovese dessa forma um aumento da projeção de 2020, com a operacionalização dos recursos disponibilizados para estados e municípios da Covid-19 (CGU, 2020).

No tocante as fraudes constatadas pela CGU (2020), com recursos da saúde, Caldas, Costa e Pagliarussi (2016), obtiveram evidências negativas com aplicação de recursos da saúde e educação pelos municípios brasileiros, isso se dá pela obrigação dessas aplicações serem reguladas, e os autores, destacaram que os fraudadores, buscam a facilidade na realização de ilícitos, em que, saúde e educação, não seriam atrativos, por seus insumos serem fornecidos por um número expressivo de empresas.

Por conseguinte, os resultados obtidos nesse estudo, não coadunam com as evidências desta pesquisa, onde se constataram atos de corrupção com recursos da saúde, de cerca de $R \$ 11,2$ bilhões de reais, observando que os operadores públicos, vislumbraram nos recursos destinados a combater à Covid-19, cerca de $\mathrm{R} \$ 457$ bilhões de reais, em uma oportunidade de praticar atos delituosos, contra a administração pública; destaca-se no estudo da fraude, a variável oportunidade, como a mais evidente nas práticas delituosas, em que o sujeito, racionaliza a falta de controle desses recursos, e que esse seria o momento propicio de cometer o ato e não ser descoberto (Rocha, 2018; Souza Louzada, 2017; Santos, 2016; Peres e Brizoti, 2016).

A atuação da CGU no controle de recursos federais liberados para Estados, municípios e Distrito federal, foi fundamental, pois, de acordo com Sodré e Silva (2010), na investigação de emendas parlamentares ao orçamento e corrupção municipal, evidenciaram a ocorrência de liberação desses recursos sem o devido controle na aplicação, por esses entes, em que, apresentaram $25 \%$ a mais de atos corruptos praticados pelos agentes públicos com essas emendas parlamentares, destaca-se que a oportunidade de praticar 0 ato delituoso, está configurado nas três metodologias que estudam a fraude, mas observa-se, que a variável oportunidade é a única sob o controle da instituição pública, pois uma vez, estabelecidos controles rígidos o sujeito racionaliza, que a possibilidade de ser detectado, sendo essa significativa, desiste de praticar a ação (Santos, 2016; Brasiliano, 2015). 
Em estudo correlato, sobre detecção de fraudes pela CGU, Paschoal, Santos e Faroni (2020), além da variável oportunidade, destacam a 'capacidade' de cometer à fraude, onde demonstram que o cargo ocupado pelo indivíduo estar relacionado com o cometimento de corrupção contra a administração pública.

No tocante a verificação da efetividade das TICs utilizadas pela CGU, constatou-se que a inteligência artificial e a Machine learning, após obter bons resultados no setor privado, passou-se a ser utilizada pela Administração pública no monitoramento de processos que utilizam recursos públicos federais. Desde 2015 a CGU aprimorou as TICs em ações preventivas e corretivas utilizadas isoladas ou conjuntamente (Alice, malha fina dos convênios, fala Brasil, E-gov e outras) no combate a atos de corrupção com verbas federais, mostrandose efetiva nessa ação, com constatações de cerca de $\mathrm{R} \$ 11,2$ bilhões de reais (Panis, 2020; Carvalho, 2020; Caldas, Costa \& Pagliatussi, 2020).

\section{Considerações Finais}

Essa pesquisa tratou de verificar se as ferramentas Tecnológicas utilizadas pela CGU, foram efetivas na detecção de fraudes no monitoramento dos recursos que foram disponibilizados na pandemia da Covid-19, utilizaram-se como teorias, as metodologias de estudo da fraude, e estudos relacionados com esse tema.

Essa pesquisa é relevante para analisar se as TICs foram capazes de promover as detecções de fraudes, uma vez que, de acordo com a ONU, FIESP, IBPT e OKBR revelaram ser robusto o índice de corrupção com recursos públicos no Brasil, onde em cálculo médio estimado de três instituições, apresentou-se cerca de $\mathrm{R} \$ 21,06$ bilhões de reais de possíveis atos de corrupção com recursos disponibilizados para combater a pandemia. Entende-se que o objetivo dessa pesquisa que buscou verificar a efetividade das Tecnologias da Informação e Comunicação (TICs) utilizadas pela CGU, foi alcançado, pois, conseguiu-se detectar as fraudes com recursos destinados à Covid-19 e verificar se as TICs foram efetivas.

Os levantamentos da busca de irregularidades, basearam-se em três aspectos, auxílio emergencial, com $\mathrm{R} \$ 1$ bilhão de reais e $\mathrm{R} \$ 8.8$ bilhões de reais, de recebimento de servidores públicos e demais cidadãos respectivamente; operações da polícia Federal, que promoveram investigações através de dados levantados pela CGU, onde foram deflagadas sete operações pela PF, com valores dos ilícitos de cerca de $R \$ 100$ milhões de reais; outras investigações que estão em andamento, através da polícia civil, CGU, Ministério Público Estaduais, por superfaturamento de preços e ilicitudes nos processos licitatórios, que apontam em cerca de R\$ 1,4 milhões de reais, depreende-se que as TICs foram utilizadas conjuntamente, em parceria com outros órgãos de controle brasileiro.

De acordo com as análises promovidas nessa pesquisa, onde se constatou irregularidades, de acordo com a Tabela 5, com montantes apresentados em $R \$ 11,2$ bilhões de reais, que de acordo com o cálculo médio para 0 custo da corrupção com recursos da Covid-19 representam cerca de $\mathrm{R} \$ 21,06$ bilhões. Dessa forma, depreende-se que as TICs utilizadas pela CGU foram efetivas no monitoramento dos recursos da Covid-19.

Com relação aos estudos relacionados com esse tema, Paschoal, Santos e Faroni (2020), também destacaram a variável oportunidade, como a mais relevante em pesquisa sobre fraude, pois, os fraudadores contam com as deficiências dos sistemas de controle; ainda, sobre as TICs, Panis (2020), evidenciou a efetividade da ferramenta Alice, que foi utilizada para detectar vícios em editais e contratos com recursos da Covid-19, além disto, Caldas, Costa e Pagliarussi (2015) evidenciaram em seu estudo a robustez da corrupção na utilização de recursos públicos, coadunando com os achados dessa pesquisa.

Como limitações dessa pesquisa destaca-se, a falta de conhecimento de quais ferramentas promovem efetivamente o auxílio na detecção de fraudes, pois, essas informações não são apresentadas individualmente pela CGU, evidencia-se que o conjunto de ferramentas ajudam na detecção de fraudes, por isso, não se sabe 


\section{Erivanilson Freitas de Oliveira, Camila Karen Alves Pedrosa, Sérgio Luiz Pedrosa Silva, Wênyka Preston Leite Batista da Costa \& Jandeson Dantas da Silva.}

qual ferramenta é a mais eficaz, ainda, pelo sigilo dos dados dos cidadãos, não se pode aprofundar a análise, através das metodologias que estudam a fraude.

Para pesquisas futuras relacionadas a esse tema, aponta-se para se buscar ferramentas de detecção de fraudes, eletrônicas utilizadas em outros países, para se realizar uma comparação com as utilizadas pela CGU no Brasil.

\section{Referências}

Abdullahi, R., \& Mansor, N. (2015). Fraud Triangle Theory and Fraud Diamond Theory. Understanding the Convergent and Divergent For Future Research. International Journal of Academic Research in Accounting, Finance and Management Sciences, 5 (4), 3845. http://dx.doi.org/10.6007//JARAFMS/v5-i3/1823

Agência Brasil (2020). Governo executa 77\% dos recursos para ações de combate à covid-19. Recuperado em 3 novembro, 2020, de https://agenciabrasil.ebc.com.br/saude/noticia/2020-10/governo-executa-77-dos-recursos-para-acoes-de-combate-a-covid-19

Anderson R. M., Heesterbeek H., Klinkenberg D. \& Hollingsworth T. D. (2020). How will country-based mitigation measures influence the course of the COVID-19 epidemic? Lancet. http://doi.org/10.1016/S0140-6736(20)30567-5

Balsa, C. A. J. (2017). Um sistema multiagente no combate ao branqueamento de capitais. Revista ibérica de Sistemas e Tecnologias de Informação, n. 25. http://DOI:10.17013/risti.25.1-17

Bardin, L. Análise de conteúdo. Lisboa: Edições 70, 2011.

Bao, Y., Bin, K., Bin, L., Yu, Y. J., Zhang, J. (2020). Detecting Accounting Fraud in Publicly Traded U.S. Firms Using a Machine Learning Approach. Journal of Accounting Research, 58 (1), 199-235. https://doi.org/10.1111/1475-679X.12292

Berlt, C., Bender Filho, R., \& Tristão, P. A. (2017). Gastos públicos: análise da aplicação da Lei de Responsabilidade Fiscal e da Constituição Federal no COREDE Alto Jacuí. Revista de Administração da Universidade Federal de Santa Maria, Santa Maria, 10 (1), 85-100, https://doi.org/10.5902/1983465910409

Bochewek, A. C., \& Pereira, J. L. (2018). Corrupção Sistêmica no Brasil: enfrentamento e dificuldades. Revista do Ministério Público do Estado do Paraná, 5 (8), 63-89, recuperado em 21 janeiro, 2021, de http://criminal.mppr.mp.br/arquivos/File/Corrupcao_sistemica_no_Brasil_Enfrentamento_e_dificuldades_.pdf

Brasiliano, A. C. R. (2015). Gestão de Risco de Fraude: Fraud Risk Assessment - FRA. São Paulo: Sicurezza.

Bataglia, M. B., \& Farranha, A. C. (2020). Corrupção, Transparência e CGU: Analisando o contexto para a implementação do direito de acesso a informação. Revista NAU Social, 10 (19), 23-50. Recuperado em 21 setembro, 2020, de https://portalseer.ufba.br/index.php/nausocial/article/view/33923/19659

Beuren, I. M. (Organizador). (2006) Como elaborar trabalhos monográficos em contabilidade: teoria e prática. São Paulo: Atlas.

Bourges, F. (2020). Digital public administration as expansion and redemption of citizen participation - The Brazilian system Fala.br. IMODEV, Open Journals, 9 (1). Recuperado em 8 setembro, 2020. De https://ojs.imodev.org/index.php/RIGO/article/view/334/515

Brasil. (2020) Regime Diferenciado de licitações públicas. Recuperado em 14 outubro, 2020, de https://www.in.gov.br/en/web/dou//lei-n-14.065-de-30-de-setembro-de-2020-280529950

Brasil. (1953) Lei 4.320/64. Estatui Normas Gerais de Direito Financeiro para elaboração e controle dos orçamentos e balanços da União, dos Estados, dos Municípios e do Distrito Federal, 1964. Recuperado em 12 outubro, 2020, de http://www.planalto.gov.br/ccivil_03/leis/44320.htm

Brasil. (2002). Decreto n 4.304/2002. Altera dispositivos do Decreto no 3.591, de 6 de setembro de 2000, que dispõe sobre o sistema de Controle Interno do Poder Executivo Federal e da outras providências. Recuperado em 23 outubro, 2020, de http://www.planalto.gov.br/ccivil_03/decreto/2002/d4304.htm

Brasil. (2015). Controladoria-Geral da União. Programa de Fiscalização em entes Federativos. Recuperado em 2 novembro 2020 , https://www.gov.br/cgu/pt-br/assuntos/auditoria-e-fiscalizacao/programa-de-fiscalizacao-em-entes-federativos 
Brasil. (2011). Lei de Acesso a Informação (LIA). Recuperado em 8 outubro, 2020, de http://www.planalto.gov.br/ccivil_03/_ato20112014/2011/lei/12527.htm

Brown-Liburd, H., Vasarhelyi, M. A. (2015). Big data and audit evidence. Journal of Emerging Technologies in Accounting, 12 (1), 1 16. https://doi.org/10.2308/jeta-10468

Carvalho, S. T. N. (2020). Impacto da inteligência artificial na atividade de auditoria: equacionando gargalos nos repasses da união para entes subnacionais. Dissertação (mestrado) - Escola Brasileira de Administração Pública e de Empresas, Centro de Formação Acadêmica e Pesquisa. 2020. $114 \mathrm{f}$.

Caldas, O. V, Costa, C. M. \& Pagliarussi, M. S. (2016). Corrupção e composição dos gastos governamentais: evidências a partir do Programa de Fiscalização por Sorteios Públicos da Controladoria-Geral da União. Revista de Administração Pública, Rio de janeiro, 50 (2), 237-264. https://doi.org/10.1590/0034-7612140185

CGU (2019). apresenta soluções inovadoras para a prevenção e o combate à corrupção. Recuperado em 4 novembro, 2020, de https://www.corregedorias.gov.br/cgu-apresenta-solucoes-inovadoras-para-a-prevencao-e-o-combate-a-corrupcao

CGU. (2020). Controladoria Geral da União. Detalhamento do benefício auxílio emergencial. Recuperado em 11 outubro, 2020, de http://www.portaltransparencia.gov.br/beneficios/auxilio-emergencial?ordenarPor=beneficiario\&direcao=asc

Chaves, T. S. S. \& Bellei N. (2020). SARS-CoV-2, o novo Coronavírus: uma reflexão sobre a Saúde Única (One Health) e a importância da medicina de viagem na emergência de novos patógenos. Revista de Medicina, [S.I.], 99 (1). http://dx.doi.org/10.11606/issn.1679-9836.v99i1pi-iv

DallagnoL, D. (2017). A luta contra a corrupção: a Lava Jato e o futuro de um país marcado pela impunidade. Rio de Janeiro: Primeira Pessoa.

Ernst, \& Young, (2009). Detecting financial statement fraud. Retrieved: 2 August 2014 from http: www.ey.com/Publication/vwLUAssets/FIDSFI

Estado de Minas. (2020). Corrupção ataca $R \$ 1,4$ bilhão destinado ao combate à covid-19. Recuperado em 28 setembro, 2020, de https://www.em.com.br/

Florêncio Filho, M. A., \& Zanon, P. B. (2020). Covid-19 e corrupção: políticas de controle em face às medidas emergenciais. Revista Pensamento Jurídico, São Paulo, 14(2), Edição Especial Covid-19. Recuperado em 4 novembro, 2020, de https://fadisp.com.br/revista/ojs/index.php/pensamentojuridico/article/view/207

FIESP (Federação das Indústrias do Estado de São Paulo. (2010). O Custo da corrupção no Brasil. Recuperado em 14 dezembro, 2020, de https://www.fiesp.com.br/noticias/custo-da-corrupcao-no-brasil-chega-a-r-69-bi-por-ano /.

Gil-Garcia \& Lanza, B. B. B. (2015). Governo Digital no Brasil e nos Estados Unidos: esforços iniciais e o status atual. Pesquisas TIC Governo Eletrônico. Recuperado em 11 outubro, de https://cgi.br/media/docs/publicacoes/2/TIC_eGOV_2015_LIVRO_ELETRONICO.pdf

Gil, A. C. (2010). Como elaborar projetos de pesquisa. 5. ed. São Paulo: Atlas.

FIESP. (2010). Relatório Corrupção: custos econômicos e propostas de com bate. Recuperado em 11 novembro, 2020, de Https://www.fiesp.com.br/noticias/custo-da-corrupcao-no-brasil-chega-a-r-69-bi-por-ano/.

IBPT (2017). Instituto Brasileiro de Planejamento Tributário. Estudo demonstra que a corrupção no país consome 29 dias de trabalho de cada cidadão. Recuperado em 14 outubro, 2020, de https:/libpt.com.br/brasileiro-trabalhara-ate-sexta-feira-2-de-junho-sopara-pagar-impostos-releva-ibpt/

Jaadi, Z. A step by step explanation of Principal Component Analysis. (2017). Recuperado em 28 abril, de 2020, de https://towardsdatascience.com/a-step-by-step-explanationof-principal-component-analysis-b836fb9c97e2

Marconi, M. de A. e Lakatos, E. M. (2009). Fundamentos de metodologia científica. 6. ed. São Paulo: Atlas.

Murdock, H. (2008). The Three Dimensions of Fraud: Internal Auditors. Recuperado em 22 abril, 2020, de www.emerald.com.

Nander, D. (2020). TCU: só 5\% devolveram auxílio emergencial recebido indevidamente.2020. Recuperado em 10 dezembro, 2020, de https://www.contabeis.com.br/noticias/45392/tcu-so-5-devolveram-auxílio-emergencial-recebido-indevidamente/ 
Open Knowledge Brasil (OKBR). (2020). Guia de transparência nas contratações emergenciais. Recuperado em 20 novembro, 2020 , de https://comunidade.transparenciainternacional.org.br/asset/86:OKBR-recomendacoes-decontratacoes-emergenciaiscovid19?stream=1

Panis, A. da C. (2020). Inovação em compras públicas: estudo de caso do robô Alice da Controladoria Geral da União (CGU)m Universidade de Brasília, Dissertação de Mestrado, 116f. Recuperado em 14 setembro, 2020, de https://repositorio.unb.br/handle/10482/38639

Paschoal, A. L. P., Santos, N. de A \& Faroni, W. (2020). Diamante da fraude: evidências empíricas nos relatórios de demandas externas do Ministério da Transparência e Controladoria Geral da União (CGU) dos municípios brasileiros. Revista Ambiente Contábil, Natal, 12 (2), 136-156. http://doi:10.21680/2176-9036.2020v12n2ID18732

Peres, J. R. \& Brizoti, N. (2016). Compliance corrupção e fraudes no mundo empresarial. 11 ed. São Paulo. Recuperado em 11 novembro, 2020, de https://www.komp.com.br/gallery/ccfme-v1-ebook2a.pdf

Queiroz, F. de L. (2016). As raízes da corrupção no Brasil: estudo de casos e lições para o futuro. Revista Em tese, Florianópolis, 13 (1), 235-242. https://doi.org/10.5007/1806-5023.2016v13n1p235

Rae, K., \& Subramaniam, N. (2008). Quality of internal control procedures: Antecedents and moderating effect on organisational justice and employee fraud. Managerial Auditing Journal, 23(2), 104- 124. https://doi.org/10.1108/02686900810839820

Rangel, L. Malha fina dos convênios. (2019). Recuperado em 14 setembro, 2020, de https://repositorio.cgu.gov.br/handle/1/43572 Acesso em; 14 set. 2020.

Revista Isto é. (2020). Brasil perde cerca de R\$ 200 bilhões por ano com corrupção diz Ministério Público Federal (MPF), 2017. Recuperado em 8 novembro, 2020, de https://istoe.com.br/brasil-perde-cerca-de-r-200-bilhoes-por-ano-com-corrupcao-diz-mpf/

Rocha, L. R. S. (2018). Combate às fraudes corporativas: a importância da interconectividade. VERITAZ. Gestão de Riscos e Compliance. Recuperado em 11 setembro, 2020, de http://veritaz.com.br/wp-content/uploads/2018/10/ebook_combate-asfraudes_Veritaz.pdf

Rodriguez-Morales A. J., Gallego V., Escalera-Antezana J. P., Méndez C. A., Zambrano LI \& Franco-Paredes C. (2020). COVID-19 in Latin América: The implications of the first confirmed case in Brazil. Travel Med Infect Dis 2020. https://doi.org/http://doi.org/10.1016/j.tmaid.2020.101613

Santos, R. de A. dos. (2016). Modelo Preditivo de fraude ocupacional nas organizações privadas. Tese de doutorado em Administração, PUC-SP. Recuperado em 14 setembro, 2020, de https://tede2.pucsp.br/handle/handle/18875

Schwarcz, L.M. (2008). Corrupção no Brasil Império. In: Avritzer, L; Bignotto, N.; Starling, H.M. (Orgs.) Corrupção: ensaios e críticas. Belo Horizonte: Editora UFMG.

Sodré, A. \& Alves, M. (2010). Relação entre emendas parlamentares e corrupção municipal no Brasil: estudo dos relatórios do programa de fiscalização da Controladoria-Geral da União. Revista de Administração Contemporânea, 14 (3), $414-433$. https://doi.org/10.1590/S1415-65552010000300003

Shalders, A. (2020). Brasil cai pelo $5^{\circ}$ ano seguido no 'Ranking da corrupção' e está empatado com a Albânia e Egito. (2020). Recuperado em 14 novembro, de https://www.bbc.com/portuguese/internacional-51216388

Souza, F. P. de \& Louzada, F. da R. (2017). O modelo de três linhas de defesa para uma gestão eficaz de riscos no âmbito do poder Executivo do Estado do Espírito Santo. Revista da CGU, Brasília, 9 (15), 659-681. Recuperado em 11 outubro, 2020, de https://repositorio.cgu.gov.br/handle/1/34389

Sousa Junior, J. H. de Raasch, M., Soares, J. C. \& Ribeiro, L.V.H.A. de S. (2020). Da Desinformação ao Caos: uma análise das Fake News frente à pandemia do Coronavírus (COVID-19) no Brasil. Cadernos de Prospecção, Salvador, 13 (2), $331-346$. http://dx.doi.org/10.9771/cp.v13i2.COVID-19.35978

Sundarkumar, G. G.; Ravi, V.; Siddeshwar, V. (2015). One-class support vector machine based undersampling: Application to churn prediction and insurance fraud detection. In: IEEE. Computational Intelligence and Computing Research (ICCIC), IEEE International Conference on. [S.I.], p. 1-7.

Stanisic, M., Radojevicit, t., \& Stanic, N. (2019). Predicting the type of auditor opinion statistic, machine learning, or a combination of the two? The European jornal of Applied economics. 16 (2), 1-58. https://doi.org/10.5937/EJAE16-21832 
Transparência Internacional Brasil (2020). Guia de transparência nas contratações emergenciais. Recuperado em 11 outubro, 2020 , de https://comunidade.transparenciainternacional.org.br/asset/86:tibr-recomendacoes-decontratacoes-emergenciaiscovid19?stream=1

Transparência Internacional Brasil (2020). Ranking de transparência no combate à Covid19. Recuperado em 23 novembro, 2020, de https://comunidade.transparenciainternacional.org.br/asset/89:tibrnotametodologicarankingcovid?stream=1

Vapnik, V. (2013). The nature of statistical learning theory. [S.I.]: Springer science \& business media. Springer.

Veloso, Roberto Carvalho. A corrupção e o PIB. PortalAZ. (2019). Recuperado em 9 novembro, 2020, de https://www.portalaz.com.br/blogs/6/opiniao/10428/a-corrupcao-e-o-pib

Wolfe, D., \& Hermanson, D. R. (2004). The fraud diamond: Considering four elements of fraud. The CPA Journal, 74 (12), $38-42$. Recuperado em 11 dezembro, 2020, de https://digitalcommons.kennesaw.edu/facpubs/1537/

\section{DADOS DOS AUTORES}

\section{Erivanilson Freitas de Oliveira}

Graduado em Ciências Contábeis pela UERN

Vínculo Institucional - UERN

Endereço: Rua Porto Velho, 80 - Alto do Sumaré

CEP: 59634-121 - Mossoró/RN - Brasil

E-mail: nilsinfreitas@gmail.com

Telefone: (84) 9482-0965

ORCID: https://orcid.org/0000-0002-1633-5249

\section{Camila Karen Alves Pedrosa}

Graduada em Ciências Contábeis pela UFERSA

Vinculo Institucional - UFERSA

Endereço: $1^{a}$ Travessa do Estudante, $n^{0} 400$ - apt ${ }^{0} 4$ - Nova Betânia

CEP: 59603-202 - Mossoró/RN - Brasil

E-mail: camilakarenn21@gmail.com

Telefone: (84) 98778-1841

ORCID: https://orcid.org/0000-0001-8511-0070

\section{Sérgio Luiz Pedrosa Silva}

Doutor em Geografia pela UFPE

Professor Adjunto do Curso de Ciências Contábeis na UERN

Endereço: Av. Mota Neto, 350 - apt 1101 - Nova Betânia

CEP: 59603-000 - Mossoró/RN - Brasil

E-mail: sergiopedrosa@uern.br

Telefone: (84) 98737-2273

ORCID: https://orcid.org/0000-0002-6490-3132

\section{Wênyka Preston Leite Batista da Costa}

Doutora em Administração pela UNP

Professora Adjunta do Curso de Ciências Contábeis na UERN

Endereço: Rua Sinhazinha Wanderley, 871 - Centro

CEP: 59650-000 - Açu/RN - Brasil

E-mail: wenykaleite@uern.br

Telefone: (84) 99806-3721

ORCID: https://orcid.org/0000-0002-6494-1454 
Erivanilson Freitas de Oliveira, Camila Karen Alves Pedrosa, Sérgio Luiz Pedrosa Silva, Wênyka Preston Leite Batista da Costa \& Jandeson Dantas da Silva.

Jandeson Dantas da Silva

Doutorando em Ciências Contábeis pela UNISINOS

Professor Assistente do Curso de Ciências Contábeis na UERN

Endereço: Rua Sinhazinha Wanderley, 871 - Centro

CEP: 59650-000 - Açu/RN - Brasil

Email: jandesondantas@uern.br

Telefone: (84) 98827-1274

ORCID: https://orcid.org/0000-0003-2189-5053

\section{Contribuição dos Autores:}

\begin{tabular}{|c|c|c|c|c|c|}
\hline Contribuição & $\begin{array}{l}\text { Erivanilson } \\
\text { Oliveira }\end{array}$ & $\begin{array}{l}\text { Camila } \\
\text { Pedrosa }\end{array}$ & $\begin{array}{l}\text { Sérgio } \\
\text { Silva }\end{array}$ & $\begin{array}{l}\text { Wênyka } \\
\text { Costa }\end{array}$ & $\begin{array}{l}\text { Jandeson } \\
\text { Silva }\end{array}$ \\
\hline 1. Concepção do assunto e tema da pesquisa & & & $\sqrt{ }$ & $\sqrt{ }$ & $\sqrt{ }$ \\
\hline 2. Definição do problema de pesquisa & & & $\sqrt{ }$ & $\sqrt{ }$ & $\sqrt{ }$ \\
\hline $\begin{array}{l}\text { 3. Desenvolvimento das hipóteses e constructos } \\
\text { da pesquisa (trabalhos teórico-empíricos) }\end{array}$ & & & $\sqrt{ }$ & $\sqrt{ }$ & $\sqrt{ }$ \\
\hline $\begin{array}{l}\text { 4. Desenvolvimento das proposições teóricas } \\
\text { (trabalhos teóricos os ensaios teóricos) }\end{array}$ & $\sqrt{ }$ & $\sqrt{ }$ & $\sqrt{ }$ & & \\
\hline 5. Desenvolvimento da plataforma teórica & $\sqrt{ }$ & $\sqrt{ }$ & $\sqrt{ }$ & & \\
\hline $\begin{array}{l}\text { 6. Delineamento dos procedimentos } \\
\text { metodológicos }\end{array}$ & & & $\sqrt{ }$ & $\sqrt{ }$ & $\sqrt{ }$ \\
\hline 7. Processo de coleta de dados & $\sqrt{ }$ & $\sqrt{ }$ & & & \\
\hline 8. Análises estatísticas & $\sqrt{ }$ & $\sqrt{ }$ & $\sqrt{ }$ & $\sqrt{ }$ & $\sqrt{ }$ \\
\hline 9. Análises e interpretações dos dados coletados & $\sqrt{ }$ & $\sqrt{ }$ & $\sqrt{ }$ & $\sqrt{ }$ & $\sqrt{ }$ \\
\hline $\begin{array}{l}\text { 10. Considerações finais ou conclusões da } \\
\text { pesquisa }\end{array}$ & $\sqrt{ }$ & $\sqrt{ }$ & $\sqrt{ }$ & $\sqrt{ }$ & $\sqrt{ }$ \\
\hline 11. Revisão crítica do manuscrito & & & $\sqrt{ }$ & $\sqrt{ }$ & $\sqrt{ }$ \\
\hline 12. Redação do manuscrito & $\sqrt{ }$ & $\sqrt{ }$ & $\sqrt{ }$ & & \\
\hline
\end{tabular}

